\title{
Immobilization of Amorphous NiB Nanoparticles on Mesoporous Supports: Superior Catalysis for Controllably Hydrolyzing $\mathrm{NaBH}_{4}$ to Release $\mathrm{H}_{2}$
}

\author{
Quanxing Liu, Jun Zhang $(\mathbb{D}$, Xigang Du, Gang Mi, and Yana Dong \\ Chemical Engineering \& Pharmaceutics School, Henan University of Science \& Technology, Luoyang 471023, China \\ Correspondence should be addressed to Jun Zhang; j-zhang@126.com
}

Received 31 May 2019; Revised 29 July 2019; Accepted 16 August 2019; Published 6 November 2019

Academic Editor: Tianlong Deng

Copyright (c) 2019 Quanxing Liu et al. This is an open access article distributed under the Creative Commons Attribution License, which permits unrestricted use, distribution, and reproduction in any medium, provided the original work is properly cited.

\begin{abstract}
Taking $\mathrm{Ni}\left(\mathrm{CH}_{3} \mathrm{COO}\right)_{2}$ and $\mathrm{NaBH}_{4}$ as the $\mathrm{Ni}$ and $\mathrm{B}$ sources and selecting three kinds of mesoporous materials (carbon nanotube (CNTs), activated carbon ( $\mathrm{AC})$, and silica $\left(\mathrm{SiO}_{2}\right)$ ) as supports, the liquid-phase reduction-in situ deposition tactics was employed to fabricate the amorphous alloy $\mathrm{NiB}$ and its corresponding supported catalysts $\left(\mathrm{NiB} / \mathrm{CNTs}, \mathrm{NiB} / \mathrm{AC}\right.$, and $\left.\mathrm{NiB} / \mathrm{SiO}_{2}\right)$ with assistance of a suitable stabilizer and ultrasonic treatment. The X-ray powder diffraction, transmission electron microscopy, and inductively coupled plasma atomic emission spectrometry were used to characterize the morphology and phase composition of the products. The catalytic activity of the four products for the hydrolytic hydrogen release in $\mathrm{NaBH}_{4}$ solution under different conditions was minutely investigated. The research results indicate that the as-fabricated products belong to amorphous alloy nanoparticles with the single phase and higher purity. The satisfactory dispersion and stronger interaction between $\mathrm{NiB}$ and $\mathrm{CNTs}$ give $\mathrm{NiB} / \mathrm{CNTs}$ the best thermal stability. All the four catalysts hold satisfactory catalysis, but their catalytic abilities are obviously discrepant, in the following order: $\mathrm{NiB} / \mathrm{CNTs}>\mathrm{NiB} / \mathrm{SiO}_{2}>\mathrm{NiB}>\mathrm{NiB} / \mathrm{AC}$. The mean reaction turnover frequency of the $\mathrm{NiB} /$ CNTs catalyst at both $318 \mathrm{~K}$ and $298 \mathrm{~K}$ separately comes up to $28206 \mathrm{ml}\left(\mathrm{H}_{2}\right) \cdot \mathrm{min}^{-1} \cdot \mathrm{g}^{-1}(\mathrm{NiB})$ and $13424 \mathrm{ml}\left(\mathrm{H}_{2}\right) \cdot \mathrm{min}^{-1} \cdot \mathrm{g}^{-1}(\mathrm{NiB})$, with an apparent activation energy of $47.37 \mathrm{~kJ} \cdot \mathrm{mol}^{-1}$. The proposed synthetic strategy could be extended to the fabrication of other similar amorphous alloy catalysts, expected for extensive application prospect.
\end{abstract}

\section{Introduction}

Hydrogen energy, with significant advantages of high energy efficiency and environmental friendliness, is recognized as a green and efficient new energy source with broad application prospects. But the hydrogen economy still faces two major challenges: one is the availability of affordable hydrogen sources, and the other is the controllable release and application of hydrogen gas. In recent years, various hydrogen production and storage strategies have been put forward, among which hydrogen storage and hydrogen release by virtue of some compounds have aroused great research interest. The sodium borohydride $\left(\mathrm{NaBH}_{4}\right)$ with theoretical hydrogen content of up to $10.6 \mathrm{wt} . \%$ is regarded as an ideal medium for hydrogen store, due to its nontoxicity, noninflammability, high stability, and dissolvability in some polar solvents (e.g., water and methanol), which has been preliminarily applied in fuel cells. The controllable and efficient hydrogen release from sodium borohydride solution requires the support of suitable catalysts. At present, most of the reported catalysts involve precious metals (such as Pt and Pd) [1-3]. Although the catalytic performance of the noble metal-based catalysts is commendable, the high price limits their large-scale commercial use. Therefore, active research for efficient and inexpensive new-type catalysts, so as to achieve the tunable and stable release of hydrogen gas from sodium borohydride, should be doubtlessly worth expecting.

$\mathrm{NiB}$, as a kind of typical metal-metalloid amorphous alloy, locates itself at the thermodynamic metastable state similar to the glass microstructure in natural environment, with the isotropic random arrangement of internal atom clusters. There is no existence of crystal defects such as grain boundaries, dislocations, and segregation in amorphous alloy materials. It is the uniform distribution of inner atoms, 
similar chemical environment, and high unsaturation of surface atoms that endow the amorphous alloy with very rich active sites. The special microstructure and surface state give its unique physical and chemical properties, making it get special attention in catalytic fields [4-7]. The catalytic materials with high activity, good selectivity, and long life could be promisingly obtained via directional design for preparation process, adjustment of composition, and electronic structure. For this purpose, according to the principle of liquid-phase reduction, we herein propose a facile fabricating tactics for the microsized $\mathrm{NiB}$ particles. Further, the catalytic performance of the resultant catalysts by immobilizing $\mathrm{NiB}$ particles on specially selected mesoporous supports (carbon nanotube, natural silica, and activated carbon) was scientifically evaluated by way of catalytically releasing hydrogen gas from the hydrolysis of $\mathrm{NaBH}_{4}$.

\section{Experimental}

2.1. Chemicals and Instruments. Nickel acetate $\left(\mathrm{Ni}\left(\mathrm{CH}_{3} \mathrm{COO}\right)_{2} \cdot 4 \mathrm{H}_{2} \mathrm{O}, \quad 99.0 \%\right)$, sodium borohydride $\left(\mathrm{NaBH}_{4}, 97.0 \%\right)$, sodium hydroxide $(\mathrm{NaOH}, 96.0 \%)$, sulfuric acid $\left(\mathrm{H}_{2} \mathrm{SO}_{4}, 98.0 \%\right)$, nitric acid $\left(\mathrm{HNO}_{3}, 68.0 \%\right)$, and polyvinylpyrrolidone $\left(\mathrm{PVP}, \mathrm{Mw}=1 \times 10^{4}\right)$ are all analytically pure reagents, without further purification. Carbon nanotubes (CNTs, MH511, Nanjing Jicang Company), silicon dioxide $\left(\mathrm{SiO}_{2}\right.$, type $\mathrm{B}$, Qingdao Ocean Company), and activated carbon (AC, Sy-720, Tianjin Damao Company) are directly used as received. The water used in the whole experiment was double distilled water prepared in our lab. The X-ray powder diffractometer (XRD, Bruker, Germany) equipped with $\mathrm{Cu}$-target $\mathrm{K}_{\alpha}$ ray $(0.154 \mathrm{~nm})$ was used to analyze phase composition of the catalyst products. The morphological observation and analysis of the products were carried out on a transmission electron microscope (TEM, JEM2100, Japan), and inductively coupled plasma emission spectrometer (ICP-OES, PE, USA) was used to determine chemical composition of the resulting products.

\subsection{Fabrication of Amorphous Alloy NiB and Loading on Various Supports}

(1) Fabrication of amorphous alloy $\mathrm{NiB}$ nanoparticles. Under the highly pure argon protection, $0.01 \mathrm{~mol}$ $\mathrm{Ni}\left(\mathrm{CH}_{3} \mathrm{COO}\right)_{2} \cdot 4 \mathrm{H}_{2} \mathrm{O}$ and $20 \mathrm{ml}$ water were successively added into a $100 \mathrm{ml}$ round-bottom flask. The flask was then placed in an ultrasonic tank with the temperature controlled at $303 \mathrm{~K}$, followed by addition of appropriate amount of PVP, producing a homogeneous solution containing $20 \mathrm{~g} \cdot \mathrm{l}^{-1} \mathrm{PVA}$ after $30 \mathrm{~min}$ ultrasonic dispersion. Analogously, adding $0.01 \mathrm{~mol}$ $\mathrm{NaBH}_{4}$ in $20 \mathrm{ml} \mathrm{NaOH}$ solution $\left(0.1 \mathrm{~mol} \cdot \mathrm{l}^{-1}\right)$ get a transparent alkaline $\mathrm{NaBH}_{4}$ solution. With the assistance of ultrasonic agitation, the above $\mathrm{NaBH}_{4}$ solution was slowly dripped to the nickel salt solution. Afterwards, the reaction was continued under the ceaseless ultrasonic agitation for another 90 minutes until no bubbles were visible. The resultant reaction mixture was taken out, centrifuged, and washed with an ethanol-water $(1: 1, \mathrm{v} / \mathrm{v})$ mixed solvent for 3-5 times. The isolated black solids were vacuum-dried for $2 \mathrm{~h}$ at $333 \mathrm{~K}$ to harvest $\mathrm{NiB}$ powders.

(2) Immobilizing $\mathrm{NiB}$ on the supports. The involved supports should be preactivated before use. For CNTs, $10 \mathrm{ml}$ mixed acid solution $\left(10 \mathrm{~mol} \cdot \mathrm{l}^{-1}, \mathrm{H}_{2} \mathrm{SO}_{4}\right.$ : $\left.\mathrm{HNO}_{3}=3: 1, \mathrm{v} / \mathrm{v}\right)$ containing proper amount of CNTs powders was heated to $328 \mathrm{~K}$, ultrasonically treated for $2 \mathrm{~h}$, and then filtrated, and washed with water to neutral. The resultant filter cake was dried in vacuum for $2 \mathrm{~h}$ at $333 \mathrm{~K}$. As for activated carbon, it should go through base leaching in $2.0 \mathrm{~mol} \cdot \mathrm{L}^{-1}$ $\mathrm{NaOH}$ solution for 30 min, prior to reflux in $2.0 \mathrm{~mol} \cdot \mathrm{L}^{-1} \mathrm{HNO}_{3}$ solution for $2 \mathrm{~h}$ at $348 \mathrm{~K}$.

The freshly pretreated CNTs $(0.5 \mathrm{~g})$ were added in $20 \mathrm{ml}$ nickel salt solution $\left(0.5 \mathrm{~mol} \cdot \mathrm{l}^{-1}\right)$, followed by ultrasonic dispersion and impregnation for $24 \mathrm{~h}$ at $303 \mathrm{~K}$ in an oil bath device. $20 \mathrm{ml}$ of the above-prepared basic $\mathrm{NaBH}_{4}$ solution was slowly added into the nickel salt solution under the ultrasonic dispersion. Afterwards, the reaction lasted for 120 min until no bubbles escaped. The resultant suspension was centrifuged and washed for 3-5 times with an ethanolwater mixed solvent $(1: 1, \mathrm{v} / \mathrm{v})$, and the collected solid product was vacuum-dried at $333 \mathrm{~K}$ for $3 \mathrm{~h}$ to obtain black powder, which was labeled as NiB/CNTs. By using similar preparing process, the amorphous alloy $\mathrm{NiB}$ particles supported separately on the activated carbon $\mathrm{AC}$ and $\mathrm{SiO}_{2}$ powder were fabricated and were marked as $\mathrm{NiB} / \mathrm{AC}$ and $\mathrm{NiB} / \mathrm{SiO}_{2}$, respectively.

2.3. Test Method of Catalytic Activity for the NiB-Based Catalysts. The amount of $\mathrm{H}_{2}$ gas generated from catalytic hydrolysis of $\mathrm{NaBH}_{4}$ solution in unit time under a given condition could be used to evaluate catalytic ability of the related catalyst. In the present study, a specially made glass container with appropriate volume was selected as the hydrolysis reactor, which was placed in a thermostatic water bath with temperature fluctuation of $\pm 0.2 \mathrm{~K}$. One of the container exit is linked with a ball dry pipe containing some softly loose glass wool, and upper end of the dry pipe connects with a vertical condenser cooled by circulating ice water for the purpose of trapping volatile matter. Afterwards, the cooled gas was introduced into an ice-water-bathed collecting trap that was filled with a suitable amount of anhydrous calcium chloride to adsorb possible gas impurity except $\mathrm{H}_{2}$. Next, the purified $\mathrm{H}_{2}$ gas generated in unit time from the $\mathrm{NaBH}_{4}$ hydrolysis under a certain condition was collected and measured in a gas water displacing tube [8]. A moderate amount of $\mathrm{NaBH}_{4}$ solution was added in the glass reactor, followed by adding a given amount of the as-prepared NiBbased catalyst. Once the hydrolysis reaction starts, the $\mathrm{H}_{2}$ gas volume liberated in unit time should be accurately recorded.

\section{Results and Discussion}

3.1. Phase Analysis of the Amorphous Alloy NiB and Supported Catalysts. The phase constitution of the as-fabricated $\mathrm{NiB}$ 
and its supported catalysts was analyzed and determined by $\mathrm{X}$-ray powder diffraction, and the results are shown in Figure 1. As clearly seen from Figure 1, for the unloaded $\mathrm{NiB}$, there exists only one wide blunt dispersion peak at $2 \theta$ angle of around $45^{\circ}$ (cf. Figure 1(a) (A)), which should be assigned to the characteristic diffraction peak of the amorphous alloy [9], and no existence of other peaks suggests the higher purity for the amorphous alloy $\mathrm{NiB}$ powders. While the $\mathrm{NiB}$ is loaded onto the surface of $\mathrm{SiO}_{2}$, the XRD pattern of the resultant complex $\mathrm{NiB} / \mathrm{SiO}_{2}$ changes a lot (cf. Figure 1(a) (B)). A very weak peak at about $45^{\circ}$ and a widened peak at $26^{\circ}$ appear, which can be attributed to the diffraction peaks about the amorphous alloy $\mathrm{NiB}$ and the nanosized $\mathrm{SiO}_{2}$ micropowders [10], respectively. For the other two supports involving same carbon matrix, namely AC and CNTs, the resulting supported catalysts $(\mathrm{NiB} / \mathrm{AC}$ and $\mathrm{NiB} / \mathrm{CNTs})$ after loading $\mathrm{NiB}$ clearly reveal almost similar XRD patterns (cf. Figures 1(a) (C) and 1(a) (D)). However, compared with $\mathrm{NiB}$ and $\mathrm{NiB} / \mathrm{SiO}_{2}$, the diffraction patterns regarding $\mathrm{NiB} / \mathrm{AC}$ and $\mathrm{NiB} / \mathrm{CNTs}$ present significant difference: besides the weaker broad peak corresponding to $\mathrm{NiB}$ at $45^{\circ}$, additional three diffraction peaks in turn appear at $2 \theta$ angle of $27^{\circ}, 34^{\circ}$, and $62^{\circ}$. Via comparing with the JCPDS data base, and with reference to the related literature [11-13], it can be identified that the stronger peak near $27^{\circ}$ should belong to characteristic diffraction of the carbon, while the other two weak peaks (at $34^{\circ}$ and $62^{\circ}$ ) could be attributed to the diffraction peaks for lattice plane (002) and (100) of irregular graphite phase. The wider peak shape and weaker peak strength signify that AC and CNTs are mainly composed of amorphous graphite nanoparticles.

3.2. Study on Thermal Stability of the NiB/CNTs Catalyst. For investigating the thermal stability of the as-fabricated catalyst, heat treatment on $\mathrm{NiB} / \mathrm{CNTs}$ for $2 \mathrm{~h}$ at different temperatures and corresponding XRD analysis after cooling to room temperature was conducted, and the relative results are presented in Figure 1(b). From the comparison between Figures 1(b) (F) and 1(b) (E), it is found that after $573 \mathrm{~K}$ heat treatment, the XRD pattern of $\mathrm{NiB} / \mathrm{CNTs}$ is basically the same as that of no heating treatment sample, with almost no change, indicating that the heat treatment at $573 \mathrm{~K}$ could not cause the phase transition, and the original phase compositions of the amorphous alloy $\mathrm{NiB}$ and support CNTs are still maintained. Via heat treatment at $773 \mathrm{k}$, the corresponding XRD pattern has evidently changed (cf. Figure $1(\mathrm{~b})$ (G)). The wide blunt peak at $45^{\circ}$ obviously gets sharper, indicating that the amorphous $\mathrm{NiB}$ is transferring to crystalline state to some extent. As the heat treatment temperature rises up to $873 \mathrm{k}$, the characteristic peak at $45^{\circ}$ has disappeared, becoming stronger and sharper diffraction peak, which manifests that the amorphous $\mathrm{NiB}$ has been completely crystallized (cf. Figure $1(\mathrm{~b})(\mathrm{H})$ ). In addition, the faint diffraction peak rising at $48^{\circ}, 52^{\circ}$, and $76^{\circ}$ can be identified as the characteristic peak of metal Ni by contrasting with the JCPDS, and the other small crystalline peaks could be attributed to the diffraction of metalloid B. When the temperature further rises to $973 \mathrm{k}$, three sharper diffraction peaks at $52^{\circ}, 45^{\circ}$, and $76^{\circ}$ could be seen (cf. Figure 1(b) (I)), which should be separately assigned to crystal face (111), (200), and (220) of metal Ni. These results show that high temperature treatment at $973 \mathrm{k}$ in air could make the carbon nanotubes to be partly burned off and induce $\mathrm{NiB}$ to be oxidized and broken down [14].

\subsection{Morphology Observation and Analysis of the NiB-Based} Catalysts. To explore the microscopic morphology and the dispersing state of the series of NiB-based products, the TEM analysis for $\mathrm{NiB}, \mathrm{NiB} / \mathrm{CNTs}, \mathrm{NiB} / \mathrm{SiO}_{2}$, and $\mathrm{NiB} / \mathrm{AC}$ was performed, with the relevant results presented in Figure 2. The unloaded $\mathrm{NiB}$ products reveal irregular granular shapes with the mean size of ca. $80 \mathrm{~nm}$, and the granules are linked with each other to form bead-chain network structure. The selected area electron diffraction photographs (cf. inserted image) clearly show the characteristic dispersion ring, further proving the amorphous phase nature of the NiB. In Figure 2(b), the fine tubular structure of carbon nanotubes can be distinguished, and the $\mathrm{NiB}$ granules with mean diameter of about $50 \mathrm{~nm}$ are evenly dispersed on the surface of the CNTs with the clear interface. From Figure 2(c), it is found that the distribution of the conglobate $\mathrm{NiB}$ on $\mathrm{SiO}_{2}$ support is relatively uneven, and the existence of clustering phenomena leads to the bigger mean size for the $\mathrm{NiB}$ granules (ca. $70 \mathrm{~nm}$ ). While the AC serves as the support, the morphology of supported catalyst $\mathrm{NiB} / \mathrm{AC}$ presents certain particularity (cf. Figure 2(d)), and the globular NiB particles reveal severe agglomeration, with the more large mean size of around $90 \mathrm{~nm}$.

\subsection{Catalytic Activity Analysis of the NiB-Based Catalysts}

3.4.1. Catalytic Activity of NiB and Its Supported Catalysts. The catalytic activity of $\mathrm{NiB} / \mathrm{CNTs}, \mathrm{NiB} / \mathrm{SiO}_{2}, \mathrm{NiB} / \mathrm{AC}$, and unsupported $\mathrm{NiB}$ powders on the hydrolysis of $\mathrm{NaBH}_{4}$ solution to generate hydrogen gas at room temperature was studied respectively, and the results are shown in Figure 3. The given experimental conditions are: the hydrolysis reaction temperature is $303 \mathrm{~K}$; the concentration of the alkaline aqueous solution of $\mathrm{NaBH}_{4}$ is $0.5 \mathrm{~mol} \cdot \mathrm{l}^{-1}$ (containing $\mathrm{NaOH} 0.1 \mathrm{~mol} \cdot \mathrm{l}^{-1}$ ), and the addition amount of the catalyst in the solution (in $\mathrm{NiB}$ terms) is $0.50 \mathrm{~g} \cdot \mathrm{l}^{-1}$. It can be seen from Figure 3 that the catalytic activity of the four NiB-based catalysts is obviously different. The catalyst NiB/CNTs with carbon nanotubes as the carrier have the strongest catalytic capacity; after the hydrolysis reaction for $22 \mathrm{~min}$, the amount of hydrogen gas released can reach the top value $(33.5 \mathrm{ml})$, and there is no induction period. The catalytic capacity of $\mathrm{NiB} / \mathrm{SiO}_{2}$ is weaker than that of $\mathrm{NiB} / \mathrm{CNTs}$, which needs $40 \mathrm{~min}$ to reach the top hydrogen release volume. However, the catalytic capacity of single amorphous alloy $\mathrm{NiB}$ is weaker than that of $\mathrm{NiB} / \mathrm{CNT}$ and $\mathrm{NiB} / \mathrm{SiO}_{2}$, but stronger than that of $\mathrm{NiB} / \mathrm{AC}$, and the time required to reach the top hydrogen generation volume is $70 \mathrm{~min}$. Accordingly, while $\mathrm{NiB} / \mathrm{AC}$ is used as the catalyst, it takes $90 \mathrm{~min}$ to reach the top hydrogen release volume, obviously holding the weakest catalytic capacity. In the initial 20 min of hydrolysis reaction, 


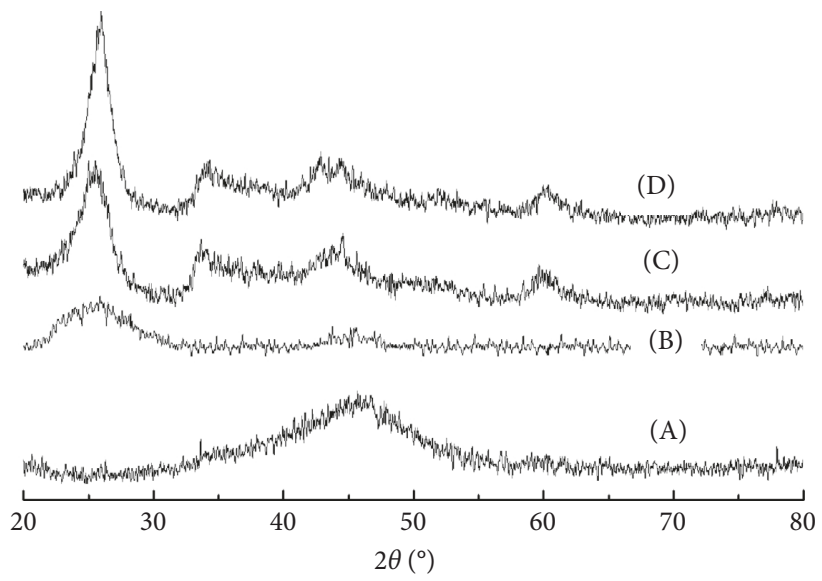

(a)

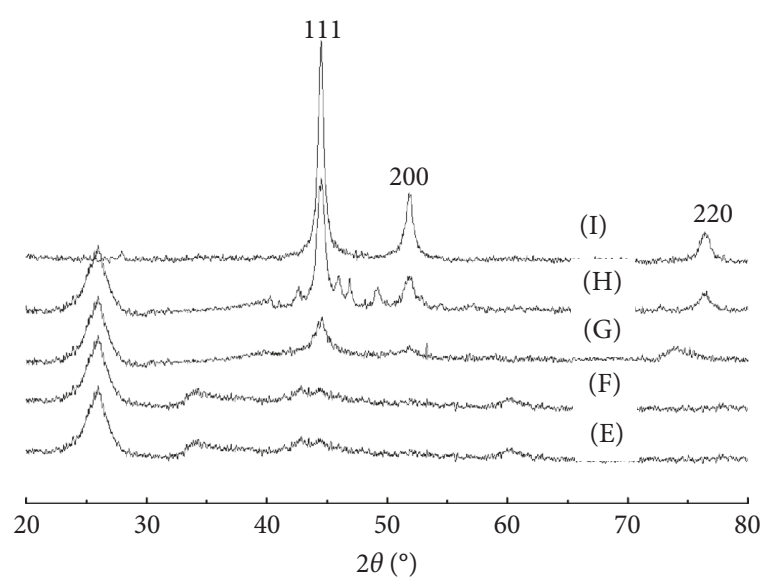

(b)

Figure 1: (a) XRD patterns of the amorphous alloy $\mathrm{NiB}$ and its supported catalyst: (A) $\mathrm{NiB},(\mathrm{B}) \mathrm{NiB} / \mathrm{SiO}_{2},(\mathrm{C}) \mathrm{NiB} / \mathrm{AC}$, and (D) NiB/CNTs; (b) XRD patterns of NiB/CNTs catalyst treated at different temperatures: (E) $303 \mathrm{~K}$, (F) $573 \mathrm{~K},(\mathrm{G}) 773 \mathrm{~K}$, (H) $873 \mathrm{~K}$, and (I) $973 \mathrm{~K}$.

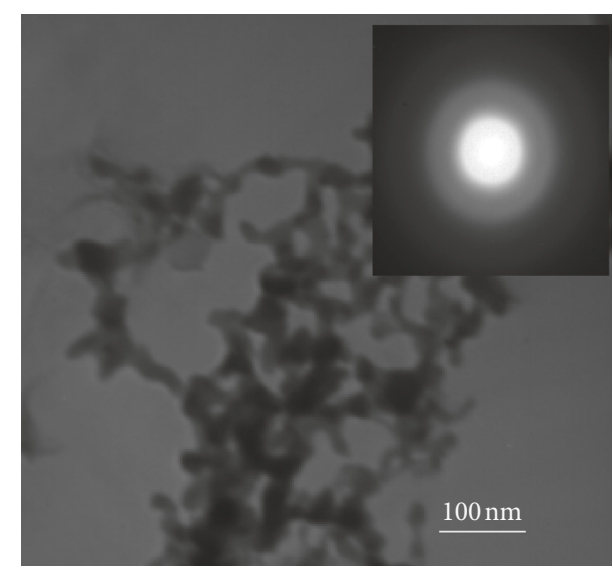

(a)

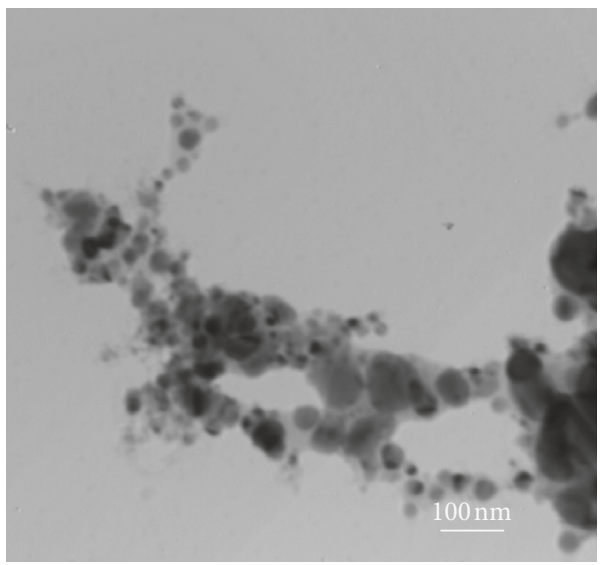

(c)

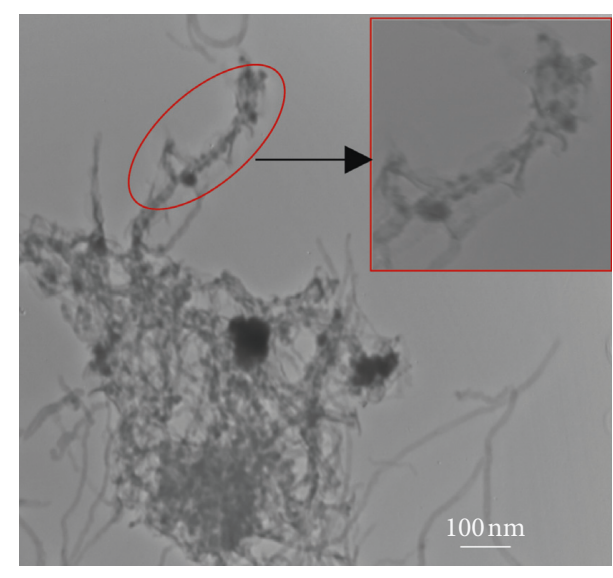

(b)

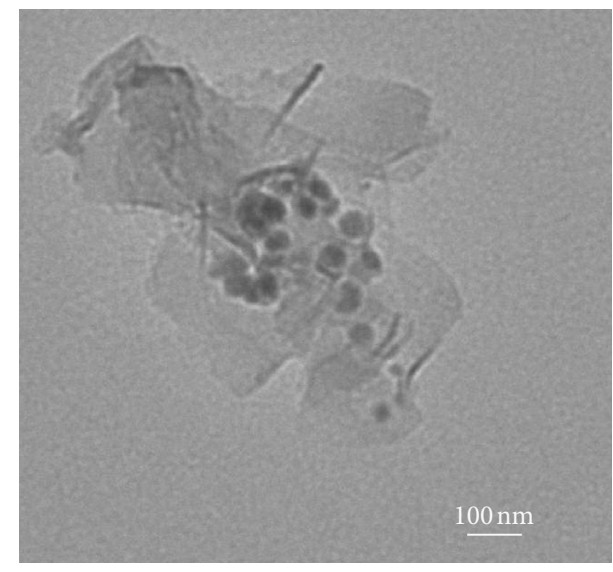

(d)

Figure 2: TEM images of the amorphous alloy $\mathrm{NiB}$ and its supported catalysts. (a) $\mathrm{NiB}$; (b) $\mathrm{NiB} / \mathrm{CNTs}$; (c) $\mathrm{NiB} / \mathrm{SiO}$; (d) $\mathrm{NiB} / \mathrm{AC}$.

by using $\mathrm{NiB} / \mathrm{CNTs}$ as catalyst hydrogen generation amount is $32.6 \mathrm{ml}$, while for the other three catalysts $\left(\mathrm{NiB} / \mathrm{SiO}_{2}, \mathrm{NiB}\right.$, $\mathrm{NiB} / \mathrm{AC}$ ) the corresponding hydrogen production amount is $22.8 \mathrm{ml}, 14.3 \mathrm{ml}$, and $9.7 \mathrm{ml}$, respectively, which can separately reach $69.9 \%, 43.8 \%$, and $29.7 \%$ of the hydrogen generation amount catalyzed by NiB/CNTs. According to the above contrast, it can be concluded that the catalytic activity of the four catalysts should follow the order: NiB/ 


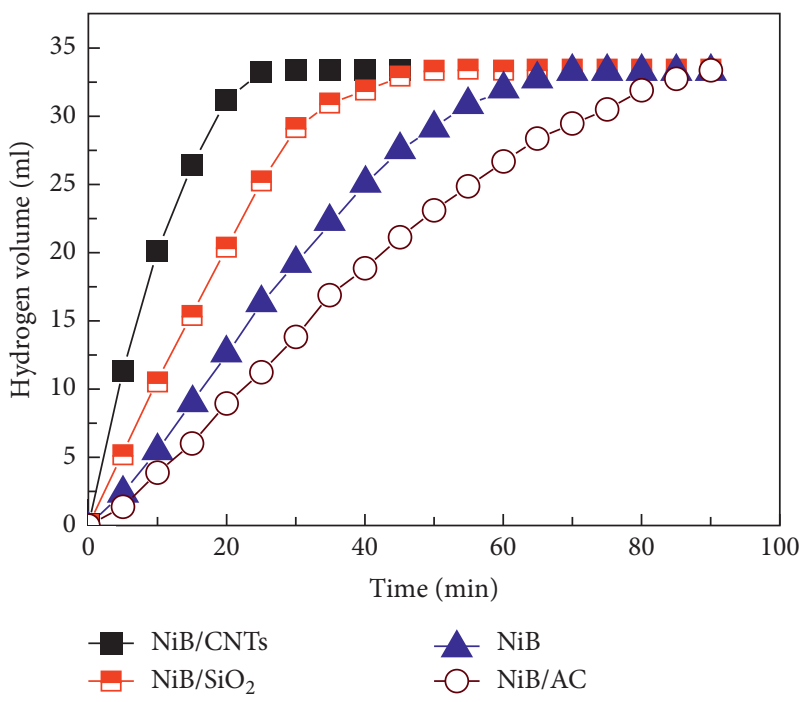

FIgURE 3: Catalytic activity test of $\mathrm{NiB}$ and the supported catalysts for catalytic hydrolysis of $\mathrm{NaBH}_{4}$ to release $\mathrm{H}_{2}$ gas.

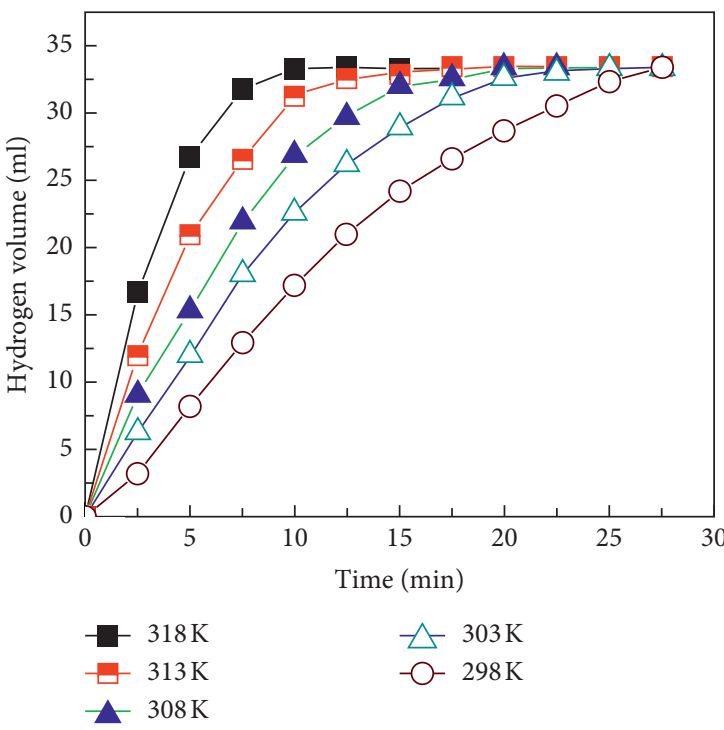

(a)

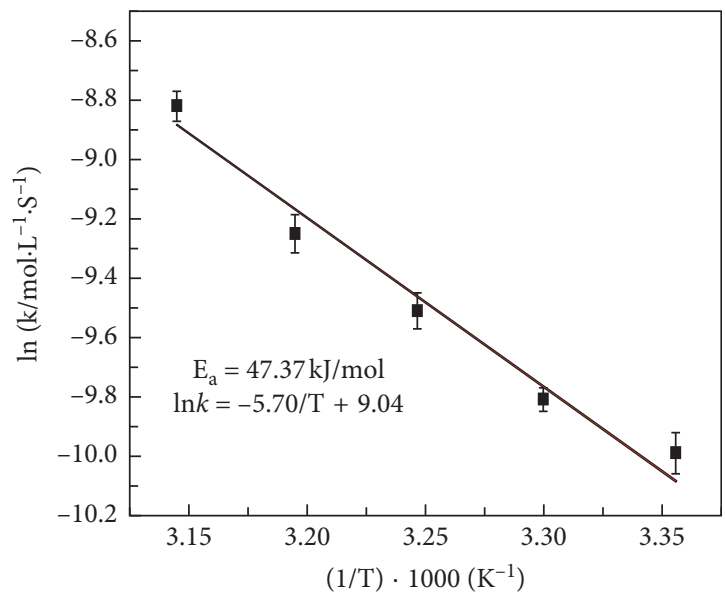

(b)

FIgURE 4: (a) Kinetic features of the hydrolytic dehydrogenation reaction catalyzed by the NiB/CNTs at different temperatures; (b) relationship between the logarithm of the hydrolysis reaction rate constant $k$ and inverse of temperature $T$.

$\mathrm{CNTs}>\mathrm{NiB} / \mathrm{SiO}_{2}>\mathrm{NiB}>\mathrm{NiB} / \mathrm{AC}$. Undoubtedly, these results certify that the catalytic activity of the NiB-based catalysts is largely influenced by the support. In fact, the research findings about the catalytic ability are also basically consistent with the aforesaid TEM analysis about the morphology and dispersion. The reason lies in that the TEM characterization results reveal that $\mathrm{NiB}$ particles loaded on CNTs have the best dispersion effect, followed by that on $\mathrm{SiO}_{2}$, and $\mathrm{AC}$ support has the worst dispersion ability. The well and uniform dispersion of $\mathrm{NiB}$ particles on the related supports can form larger specific surface area and afford more active sites, correspondingly prompting the catalytic activity.
3.4.2. Catalytic Activity of NiB/CNTs Catalysts at Different Temperatures. Different hydrolysis temperatures not only influence the catalytic performance of the catalysts, but also affect the kinetic features of the hydrolysis reaction. Therefore, we further studied the impact of $\mathrm{NiB} / \mathrm{CNTs}$ as catalyst on the hydrolytic dehydrogenation in $\mathrm{NaBH}_{4}$ solution at different temperatures (from 298 to $318 \mathrm{k}$ ), and the experimental results are shown in Figure 4. On the whole, within the initial $10 \mathrm{~min}$ of the hydrolytic reaction, the amount of hydrogen gas generated under the five temperatures increases gradually with the rise in temperature. For the highest temperature of $318 \mathrm{~K}$, the hydrogen release amount in $10 \mathrm{~min}$ is $32.3 \mathrm{ml}$, almost near the maximum 
$(33.5 \mathrm{ml})$, while the hydrogen release volume at the lowest temperature of $298 \mathrm{~K}$ is $16.6 \mathrm{ml}$, only attaining $51.4 \%$ of the hydrogen release amount at $318 \mathrm{~K}$. At the other three temperatures $(313 \mathrm{~K}, 308 \mathrm{~K}$, and $303 \mathrm{~K})$, the hydrogen amounts released in the initial $10 \mathrm{~min}$ are successively $31.1 \mathrm{ml}, 27.4 \mathrm{ml}$ and $22.6 \mathrm{ml}$, which can separately attain $96.3 \%, 84.8 \%$, and $69.9 \%$ of the hydrogen amount released at the highest temperature $(318 \mathrm{~K})$. To attain the maximal hydrogen release volume $(33.5 \mathrm{ml})$, the reaction time required at the five temperatures (from low to high) is $29 \mathrm{~min}$, $26 \mathrm{~min}, 21 \mathrm{~min}, 16 \mathrm{~min}$ and $12.5 \mathrm{~min}$, respectively. The reaction rates of hydrolytic hydrogen release catalyzed by the NiB-based catalysts are all incremental with the temperature rise before reaching the top hydrogen production and without any induction period, revealing the positive correlation of the catalytic ability with temperature. Based on the above experimental data, the mean turnover frequency (TOF) of the $\mathrm{NiB} / \mathrm{CNT}$ catalyst in the initial phase at both the high and low temperatures $(318 \mathrm{~K}$ and $298 \mathrm{~K}$ ) can be determined, which separately comes up to the pretty high values: $28206 \mathrm{ml}\left(\mathrm{H}_{2}\right) \cdot \mathrm{min}^{-1} \cdot \mathrm{g}^{-1}(\mathrm{NiB})$ and $13424 \mathrm{ml}\left(\mathrm{H}_{2}\right)$. $\min ^{-1} \cdot \mathrm{g}^{-1}$ (NiB) (both in $\mathrm{NiB}$ terms).

According to the principle of chemical kinetics, and via analyzing the change rules of hydrolytic process, it could be found that the hydrolysis reaction catalyzed by $\mathrm{NiB} / \mathrm{CNTs}$ reveals the characteristics of zero-order reaction kinetics, that is, presenting satisfactory linearity between hydrogen release amount and reaction time [15]. By means of the data about hydrogen release rate at different temperatures, the corresponding rate constant $(k)$ can be calculated, and thus the relationship between the logarithm of the rate constant and the inverse of the reaction temperature $(1 / T)$ can be depicted, just as shown in Figure 4(b). In accordance with the Arrhenius equation: $\ln (k)=-(\mathrm{Ea} / \mathrm{RT})+\mathrm{C}$, the apparent activation energy (Ea) of the hydrolytic dehydrogenation reaction can be determined to be $47.37 \mathrm{~kJ} \cdot \mathrm{mol}^{-1}$. By reference to relevant reports, the apparent activation energy of the $\mathrm{NaBH}_{4}$ hydrolysis reaction catalyzed by metal $\mathrm{Ni}$ [16] and $\mathrm{CoB}$ [17] under the same condition is $71 \mathrm{~kJ} \cdot \mathrm{mol}^{-1}$ and $68.87 \mathrm{~kJ} \cdot \mathrm{mol}^{-1}$, respectively, evidently exceeding that of $\mathrm{NiB} /$ CNTs, which testifies the superior catalytic activity of $\mathrm{NiB} /$ CNTs, with a good potential application value.

\section{Conclusion}

Via liquid-phase reduction-in situ deposition tactics, the $\mathrm{NiB}$ particles and their supported catalysts (NiB/CNTs, NiB/ $\mathrm{AC}$, and $\mathrm{NiB} / \mathrm{SiO}_{2}$ ) were successfully fabricated. Meanwhile, the phase constitution and shape of the products were characterized, and their catalytic activities for hydrolyzing $\mathrm{NaBH}_{4}$ at different temperatures were systematically evaluated. The following conclusions could be drawn: (1) The liquid-phase reduction-in situ deposition route could be used to fabricate the amorphous alloy $\mathrm{NiB}$ nanoparticles with pure phase and good dispersion, and the stable immobilization on the three mesoporous supports can be achieved. (2) The catalyst NiB/CNTs has excellent thermal stability and can keep the stable phase structure even at $773 \mathrm{~K}$. (3) All the four NiB-based catalysts hold good catalytic activity for hydrolyzing $\mathrm{NaBH}_{4}$; by comparison, $\mathrm{NiB} / \mathrm{CNTs}$ has the strongest catalytic activity, and that of $\mathrm{NiB} / \mathrm{AC}$ is weakest. (4) The catalytic activity of $\mathrm{NiB} / \mathrm{CNTs}$ is positively correlated with the hydrolysis temperature, and rising temperature helps to prompt its catalytic ability; at $318 \mathrm{~K}$ and $298 \mathrm{~K}$, the mean TOF values of the hydrolytic hydrogen release reaction catalyzed by the $\mathrm{NiB} / \mathrm{CNTs}$ are $28206 \mathrm{ml}\left(\mathrm{H}_{2}\right) \cdot \mathrm{min}^{-1} \cdot \mathrm{g}^{-1}(\mathrm{NiB})$ and $13424 \mathrm{ml}\left(\mathrm{H}_{2}\right) \cdot \mathrm{min}^{-1} \cdot \mathrm{g}^{-1}$ $(\mathrm{NiB})$, respectively, with the apparent activation energy of $47.37 \mathrm{~kJ} \cdot \mathrm{mol}^{-1}$.

\section{Data Availability}

The specific experimental data used for depicting the figures of this study are available from the corresponding author upon request.

\section{Conflicts of Interest}

The authors declare that they have no conflicts of interest.

\section{Acknowledgments}

The authors gratefully appreciate the financial supports of the National Natural Science Foundation of China (Grant nos. 21576073 and 21076063).

\section{References}

[1] M. A. Rosen and S. Koohi-Fayegh, "The prospects for hydrogen as an energy carrier: an overview of hydrogen energy and hydrogen energy systems," Energy, Ecology and Environment, vol. 1, no. 1, pp. 10-29, 2016.

[2] J.-X. Kang, T.-W. Chen, D.-F. Zhang, and L. Guo, "PtNiAu trimetallic nanoalloys enabled by a digestive-assisted process as highly efficient catalyst for hydrogen generation," Nano Energy, vol. 23, pp. 145-152, 2016.

[3] W. Chen, L. Z. Ouyang, J. W. Liu, and X. D. Yao, "Hydrolysis and regeneration of sodium borohydride $\left(\mathrm{NaBH}_{4}\right)$-a combination of hydrogen production," Journal of Power Sources, vol. 359, pp. 400-407, 2017.

[4] H. Song, X. Wu, H. Wang, and F. Li, "Promoting effects of Pt on the catalytic performance of supported $\mathrm{NiB}$ amorphous alloy catalysts for benzene hydrogenation," Chinese Journal of Chemical Engineering, vol. 19, no. 4, pp. 698-702, 2011.

[5] J. Zhang, C. Li, L. Li, and X. Du, "Multi-shaped amorphous alloy Ni-B: ultrasonically aided complexing-reduction preparation, catalytic ability for $\mathrm{NaBH}_{4}$ hydrolysis yielding $\mathrm{H}_{2}$ gas," Zeitschrift für Anorganische Chemie, vol. 640, no. 2, pp. pp456-pp461, 2014.

[6] S. Zhang, Y. Zheng, L. Yuan, and L. Zhao, "Ni-B amorphous alloy nanoparticles modified nanoporous $\mathrm{Cu}$ toward ethanol oxidation in alkaline medium," Journal of Power Sources, vol. 247, pp. 428-436, 2014.

[7] W. Huo, H. Yuan, M. Jia et al., "Preparation, characterization of $\mathrm{NiB}$ amorphous alloy nanoparticles and their catalytic performance in hydrogenation reactions," Journal of Nanoscience and Nanotechnology, vol. 13, pp. 29-34, 2013.

[8] J. Zhang, Y. Duan, Y. Zhu, Y. Wang, H. Yao, and G. Mi, "Evenly dispersed microspherical amorphous alloy $\mathrm{Co}_{\mathrm{x}} \mathrm{B}_{1-\mathrm{x}}$ : robust and magnetically recyclable catalyst for alcoholyzing ammonia borane to release $\mathrm{H}_{2}$," Materials Chemistry and Physics, vol. 201, pp. 297-301, 2017. 
[9] J. Guo, Y. Hou, C. Yang, Y. Wang, H. He, and W. Li, "Preparation of Ni-B amorphous alloy catalyst from nickel hydrazine complex with ultrasonic assistance," Catalysis Communications, vol. 16, no. 1, pp. 86-89, 2011.

[10] X. Zhang, A. Ma, X. Mu, and E. Min, "Selective hydrogenation of reformate oils over amorphous $\mathrm{NiB} / \mathrm{SiO}_{2}$ catalyst," $\mathrm{Ca}$ talysis Today, vol. 74, no. 1-2, pp. 77-84, 2002.

[11] M. S. Shamsuddin, N. R. N. Yusoff, and M. A. Sulaiman, "Synthesis and characterization of activated carbon produced from kenaf core fiber using $\mathrm{H}_{3} \mathrm{PO}_{4}$ activation," Procedia Chemistry, vol. 19, pp. 558-565, 2016.

[12] P. Wu, L. Xia, M. Dai, L. Lin, and S. Song, "Electrosorption of fluoride on $\mathrm{TiO}_{2}$-loaded activated carbon in water," Colloids and Surfaces A: Physicochemical and Engineering Aspects, vol. 502, pp. 66-73, 2016.

[13] Z. Cheng, B. Cao, and Z. Liu, "Halloysite nanotubes-templated one-step preparation for carbon nanotubes/carbon nanorods mixed carbon nanomaterials," Chinese Journal of Inorganic Chemistry, vol. 34, pp. 1801-1816, 2018.

[14] W. Liu, R. Chen, L. Liu, S. Li, Z. Xue, and C. He, "Amorphous $\mathrm{NiB} /$ carbon nanohybrids: synthesis and catalytic enhancement induced by electron transfer," RSC Advances, vol. 6, no. 97, pp. 94451-94458, 2016.

[15] A. K. Figen, "Dehydrogenation characteristics of ammonia borane via boron-based catalysts (Co-B, Ni-B, Cu-B) under different hydrolysis conditions," International Journal of Hydrogen Energy, vol. 38, no. 22, pp. 9186-9197, 2013.

[16] J. Kim, H. Lee, and S. C. Han, "Production of hydrogen from sodium borohydride in alkaline solution: development of catalyst with high performance," International Journal of Hydrogen Energy, vol. 29, no. 3, pp. 263-267, 2004.

[17] S. U. Jeong, R. K. Kim, E. A. Cho et al., "A study on hydrogen generation from $\mathrm{NaBH}_{4}$ solution using the high-performance Co-B catalyst," Journal of Power Sources, vol. 144, no. 1, pp. pp129-pp134, 2005. 

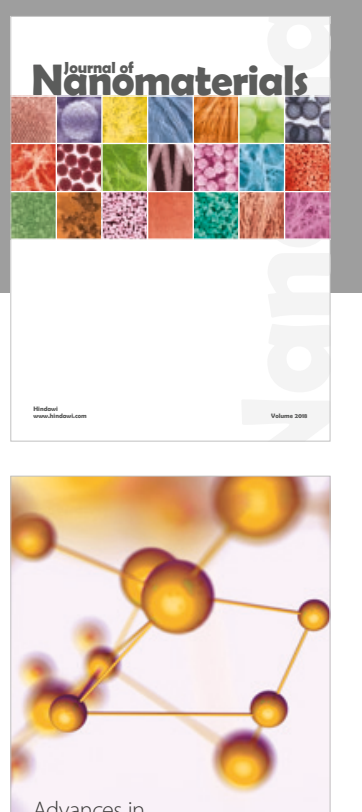

Physical Chemistry
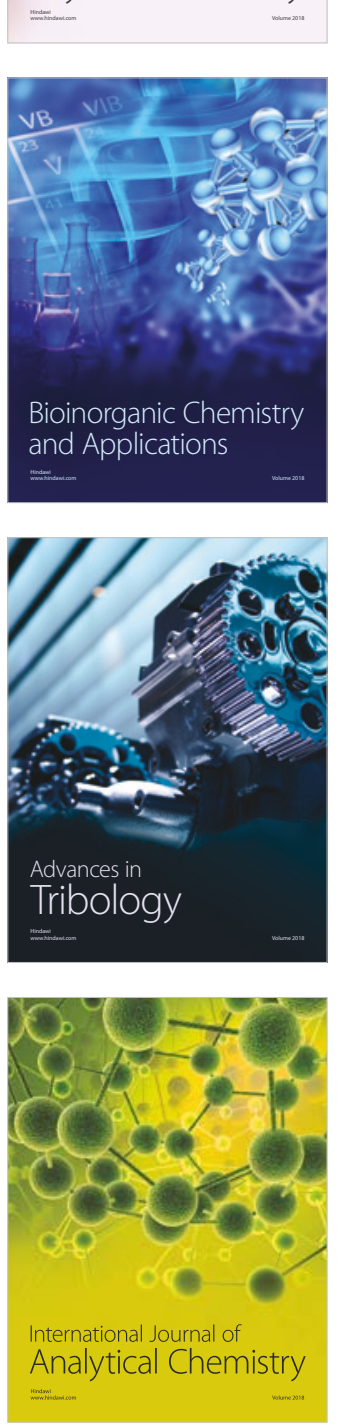

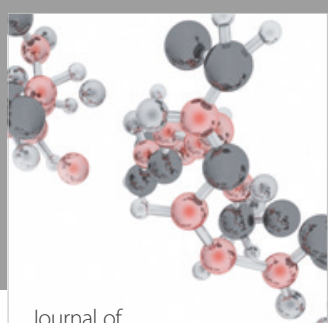

Analytical Methods

in Chemistry

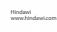

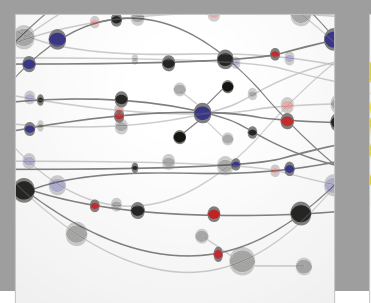

The Scientific World Journal

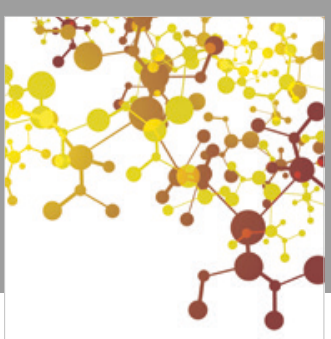

Journal of

Applied Chemistry
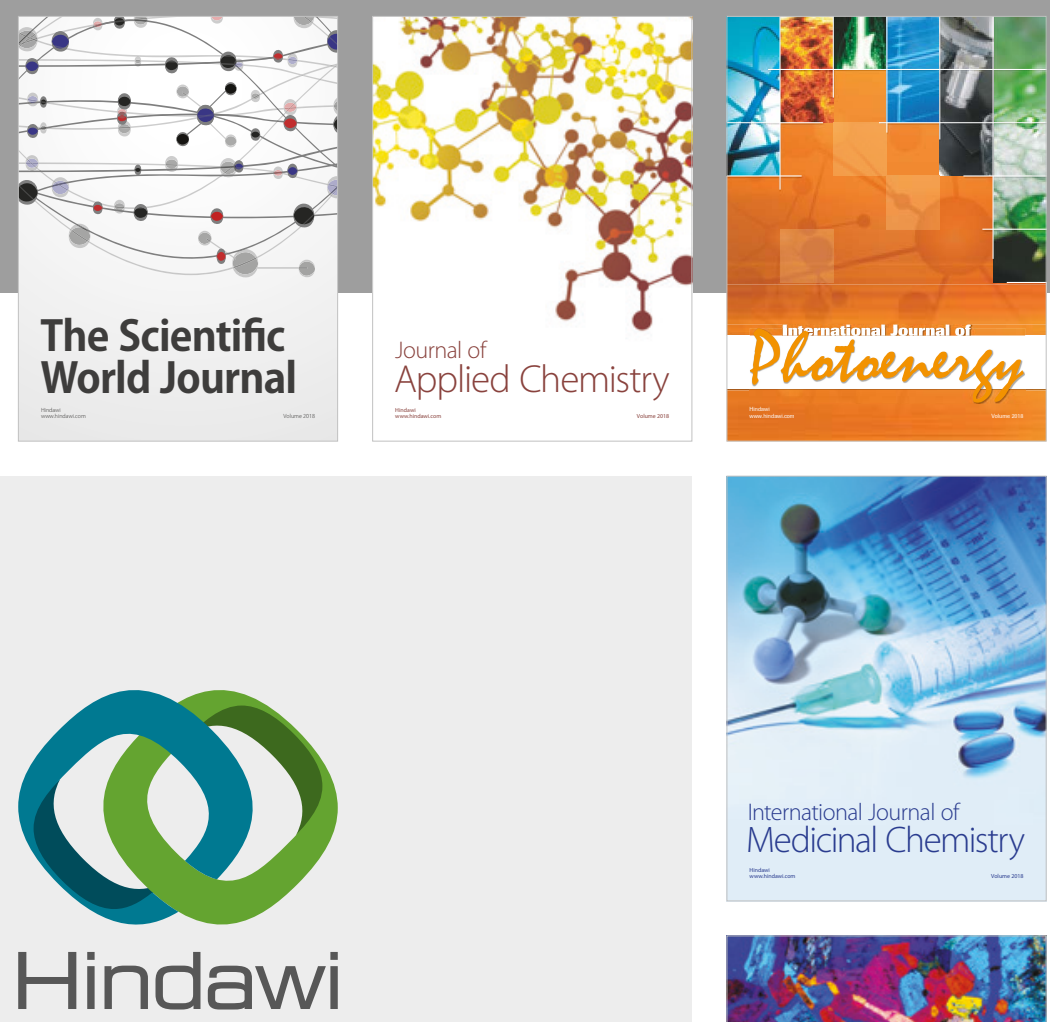

Submit your manuscripts at

www.hindawi.com
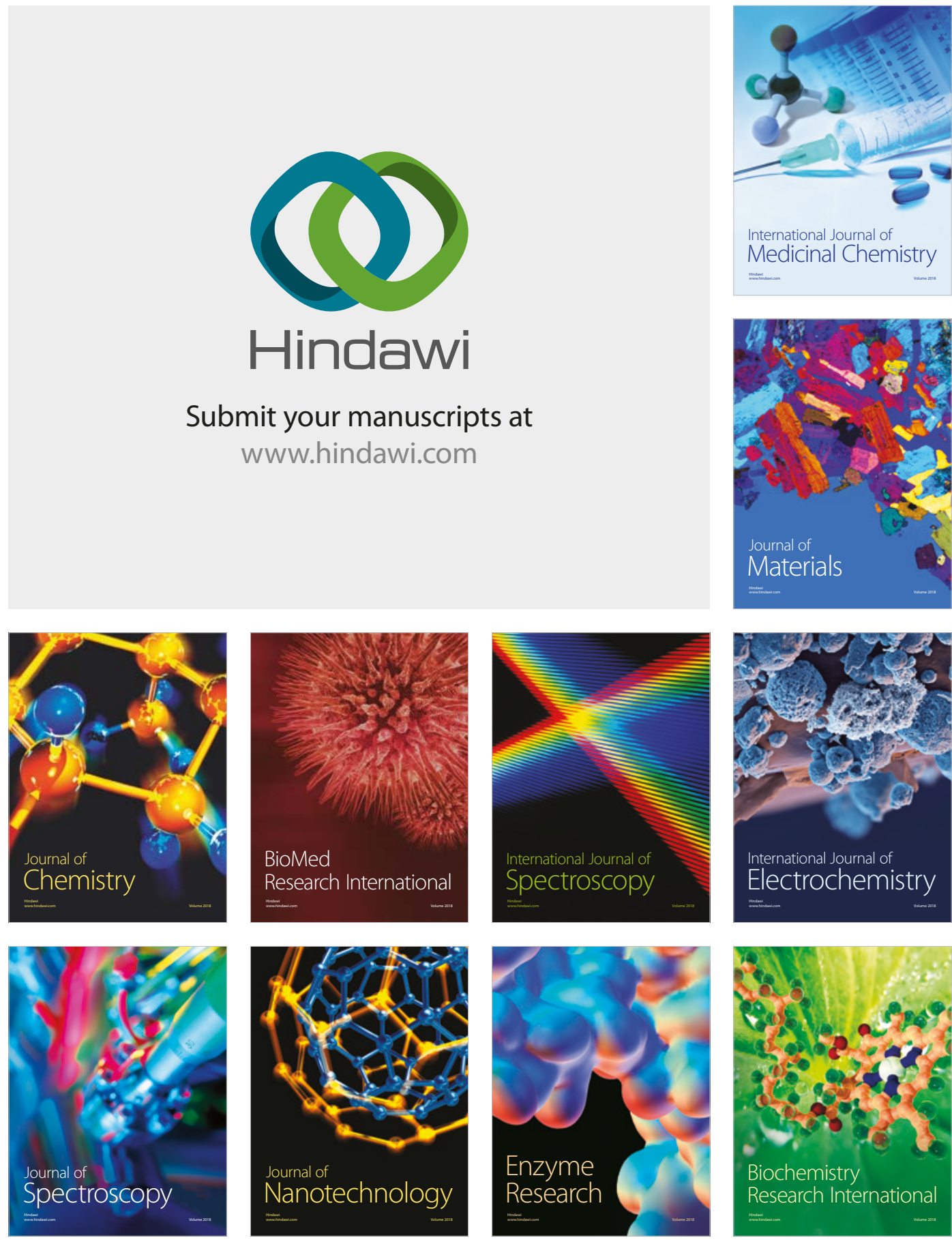
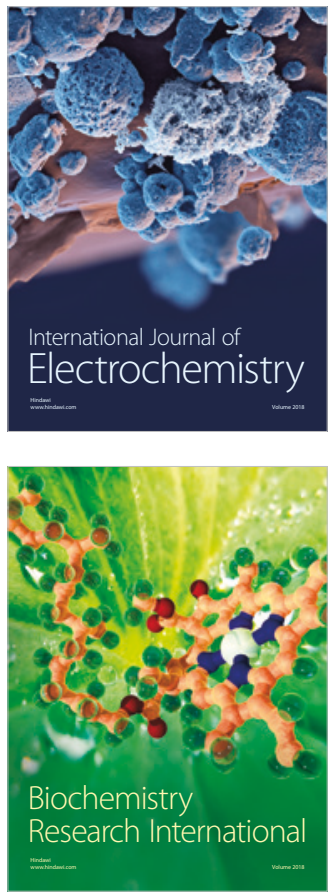